\title{
Lewis acidic metal catalysed organic transformations by designed multi-component structures and assemblies
}

\author{
AFSAR ALI, AMIT P SINGH and RAJEEV GUPTA* \\ Department of Chemistry, University of Delhi, Delhi 110007 \\ e-mail: rgupta@chemistry.du.ac.in
}

MS received 27 October 2009; revised 25 February 2010; accepted 2 March 2010

\begin{abstract}
This paper presents the recent developments in designing multi-component structures including metal-organic frameworks containing Lewis acidic metal ions. The emphasis has been given to understand the design elements adopted to synthesize such structures bearing Lewis acidic metal ion. Further, few important Lewis acidic metal catalysed organic transformation reactions have been discussed demonstrating the importance of such materials for practical purposes.
\end{abstract}

Keywords. Multi-component structures; Lewis acidic metals; organic transformations.

\section{Introduction}

Zeolites have been the epitome of catalysis where reaction takes place within the pores and channels of the material. ${ }^{1}$ The large surface area offered by the zeolites and uniformity of their pores and channels are the main factors responsible for their catalytic applications. $^{2}$ Zeolites are normally synthesized under harsh reaction condition and retain their structure even at very high temperature. ${ }^{3}$ This particular property of the zeolite has been extremely important in high-temperature catalysis such as petroleum cracking. However, there are several drawbacks with zeolite. Firstly, the chemical and structural diversity of zeolites is rather limited due to the exclusive use of $\mathrm{SiO}_{4} / \mathrm{AlO}_{4}$ building blocks. Second, the desirable chemical modification within the interior of the material has limitations. Such chemical modifications are important for expanding and enhancing the catalytic performance of the resultant material. Third, the catalytic applications of zeolites are restricted to relatively small organic molecules due to the limited size of pores and channels. Such drawbacks have led scientists to look for other alternate porous materials. ${ }^{4}$ In this context, designed multi-components structures including metal-organic frameworks (MOFs) and metal-organic coordination networks (MOCNs) offer unique opportunities. ${ }^{5}$

\footnotetext{
*For correspondence
}

In recent times, there has been tremendous progress in the design and synthesis of functional MOFs and MOCNs bearing structural similarities to that of zeolites. ${ }^{6}$ In contrast to the zeolites, MOFs and MOCNs are typically synthesized under mild conditions. MOFs and MOCNs share some of the catalytically relevant features of zeolites such as the large internal surface areas and uniform pore and cavity sizes. ${ }^{7}$ They, however, also differ in several ways. First, compared to high thermal stability of zeolites, MOFs and MOCNs tend to decompose at elevated temperatures. This particular feature indicates the high-temperature catalytic limitation of MOFs and MOCNs. Second, while many MOFs and MOCNs exhibit zeolite-like permanent microporosity, others collapse when solvent is removed. Third, due to the involvement of organic components, MOFs and MOCNs can be synthesized in considerable greater chemical varieties than zeolites. Fourth, chemical modifications allow rational design of MOFs and MOCNs by incorporating bridging ligands with desirable size, shape, electronic, and chiral properties.

The traditional approach to Lewis acid based catalysis is progressing rapidly towards the design and utilization of heterogeneous, reusable, and highly tolerant catalysts. In this context, porous MOFs, MOCNs and other multi-component structures and assemblies may offer an interesting alternative for their intrinsic zeolite mimicking size- and shapeselective properties. There are a few potential 
strategies to incorporate catalytically active Lewis acidic metal centre in MOFs and MOCNs. One of the approaches is to utilize catalytically active Lewis acidic metal ions with unsaturated coordination environments as nodes. In such a situation, the metal ions as nodes have coordinated solvent molecules that can be removed and/or replaced during the catalytic reactions. However, one must ensure that such a removal and/or replacement of the coordinated solvent molecules does not lead to the distortion of the framework structure. In an alternate approach, the catalytic Lewis acidic sites are placed in suitable position after the construction of the framework.

The present paper briefly describes the general design-based strategies adopted for the synthesis of MOFs, MOCNs, and other multi-component structures carrying Lewis acidic metal ions. This is followed by a brief survey of the catalytic reactions and transformations by such systems that have appeared in the literature in the last decade. It may, however, be noted that we highlight the concepts of Lewis acid based catalysis rather than scopes of reactivity and limitations.

\section{MOFs and their role in organic transformations}

The first example of catalysis by a coordination based two-dimensional (2D) network was reported by the Fujita and co-workers in $1994 .{ }^{8}$ They synthesized a square-grid network by treating $\mathrm{Cd}\left(\mathrm{NO}_{3}\right)_{2}$ with 4,4'-bipyridine that resulted in a square-grid network complex, $\quad\left[\mathrm{Cd}\left(4,4^{\prime} \text {-bipyridine }\right)_{2}\left(\mathrm{H}_{2} \mathrm{O}\right)_{2}\right.$ $\left.\left(\mathrm{NO}_{3}\right)_{2}\right]_{\alpha} 1$ (scheme 1). In this complex, each $\mathrm{Cd}^{\mathrm{II}}$ ion is hexa-coordinate with four pyridyl groups at the equatorial position and two water molecules at the apical positions. Interestingly, the nitrate ions existed independently in the grid. A unique character of the network 1 was its ability to catalyse the cyanosilylation reaction of the aldehyde that resulted in the formation of corresponding nitrile product (scheme 2). The reaction was concluded to be promoted by the heterogeneous 1 , since no reaction took place with powdered $\mathrm{Cd}\left(\mathrm{NO}_{3}\right)_{2}$ or $4,4^{\prime}$ bipyridine alone or with the supernatant liquid of a $\mathrm{CH}_{2} \mathrm{Cl}_{2}$ suspension of 1 .

The authors in their 2004 paper $^{9}$ used $\mathbf{1}$ for the cyanosilylation reaction of imine that resulted in the quantitative formation of aminonitrile (scheme 3 ). The heterogeneous nature of $\mathbf{1}$ was proved by removing the catalyst by filtration during the course of the catalytic reaction and that stopped the conversion. The authors compared the catalytic performance of complex 1 with that of $\left.[\mathrm{Cd} \text { (pyridine })_{4}\right]\left(\mathrm{NO}_{3}\right)_{2}$ (2) where the $\mathrm{Cd}(\mathrm{II})$ ion has partial structure of $\mathbf{1}$. Surprisingly, despite moderate solubility in $\mathrm{CH}_{2} \mathrm{Cl}_{2}$, the complex 2 promoted the reaction less efficiently. This result suggests that hydrophobic cavities of 1 bind substrate efficiently to promote the rapid reaction. Interestingly, $\mathrm{Cd}\left(\mathrm{NO}_{3}\right)_{2} \cdot 4 \mathrm{H}_{2} \mathrm{O}$ also poorly promoted the same reaction. The difference in the catalytic activity was explained by the comparison of the crystal structures of 1 and $\mathrm{Cd}\left(\mathrm{NO}_{3}\right)_{2} \cdot 4 \mathrm{H}_{2} \mathrm{O}$. In 1 , each $\mathrm{Cd}^{\mathrm{II}}$ ion is hexa-coordinate with four pyridyl groups at the equatorial position and two water molecules at the apical positions. While in $\mathrm{Cd}\left(\mathrm{NO}_{3}\right)_{2}$. $4 \mathrm{H}_{2} \mathrm{O}, \mathrm{Cd}(\mathrm{II})$ ion has an octa-coordinate environment with four water molecules at the equatorial positions and two nitrate ions at the apical positions. As a result of lesser coordination number, the $\mathrm{Cd}^{\mathrm{II}}$ centre of square-grid complex 1 was postulated to be more cationic than that of $\mathrm{Cd}\left(\mathrm{NO}_{3}\right)_{2} \cdot 4 \mathrm{H}_{2} \mathrm{O}$ and thus the Lewis acidity increased.

Long and co-workers ${ }^{10}$ have recently synthesized sodalite-type compound $\mathrm{Mn}_{3}\left[\left(\mathrm{Mn}_{4} \mathrm{Cl}\right)_{3}(\mathrm{BTT})_{8}\right.$

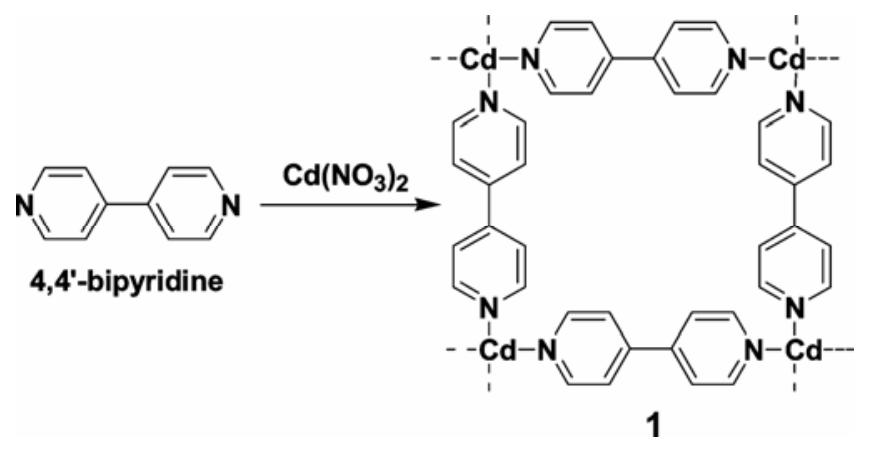

Scheme 1.

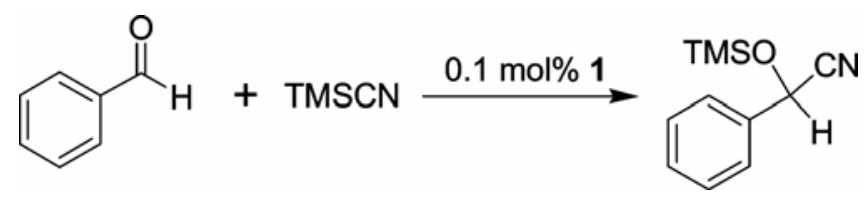

Scheme 2.

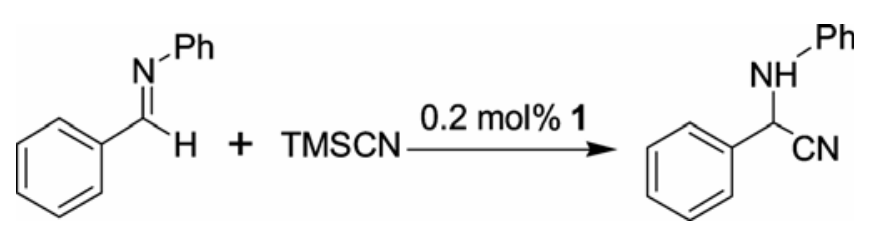

Scheme 3. 
$\left.\left(\mathrm{CH}_{3} \mathrm{OH}\right)_{10}\right]_{2} 3\left(\mathrm{H}_{3} \mathrm{BTT}=1,3,5\right.$-benzene-tristetrazol5 -yl) wherein $\mathrm{Mn}^{2+}$ ions are exposed on the surface of the framework (scheme 4). The authors have suggested that such exposed metal ion surface might serve as potent Lewis acids and catalyse the organic transformation reactions. Complex 3 indeed catalysed the cyanosilylation of aromatic aldehyde and ketones (scheme 2), as well as the more demanding Mukaiyama-aldol reaction (Scheme 5). Moreover, in each case, a pronounced size-selectivity effect consistent with the pore dimensions was observed. The compound $\mathbf{3}$ is a thermally stable microporous solid exhibiting a cubic network. The pores are readily accessible and present a surface lined with two different types of $\mathrm{Mn}^{\mathrm{II}}$ sites that differ in the coordination environment. However, both types of coordinatively unsaturated metal centres were found to be well-positioned to interact with the guest molecules that enter the framework pores, elaborating the observed Lewis acid promoted reactions that took place in a heterogeneous manner.

Tanaka and co-workers ${ }^{11}$ were able to synthesize a chiral metal-organic framework by treating enantiopure 2,2'-dihydroxy-1,1'-binaphthalene-5,5'dicarboxylic acid $\left(5,5^{\prime}-\mathrm{H}_{2} \mathrm{BDA}\right)$ with $\mathrm{Cu}\left(\mathrm{NO}_{3}\right)_{2}$ in aqueous $\mathrm{MeOH}$ (scheme 6). The enantiomerically pure complex was formulated as $\left[\mathrm{Cu}_{2}\left(5,5^{\prime}-\mathrm{BDA}\right)_{2}\right.$ $\left.\left(\mathrm{H}_{2} \mathrm{O}\right)_{2}\right]$ 4. The enantiomeric nature of $\mathbf{4}$ in the solid state was demonstrated by the solid-state CD spectra. In 4 , each $\mathrm{Cu}(\mathrm{II})$ ion was coordinated by four carboxylate oxygen atoms of ligand and each pair of $\mathrm{Cu}$ (II) ion was bridged by four carboxylate groups to form a $2 \mathrm{D}$ dinuclear square-grid coordination
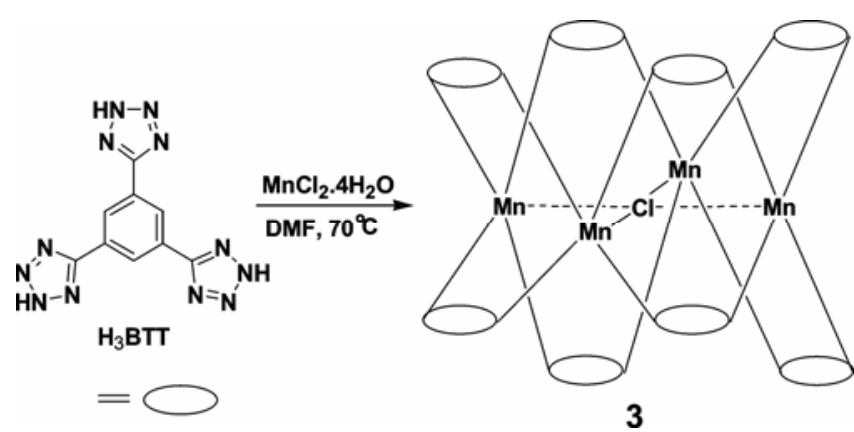

Scheme 4.

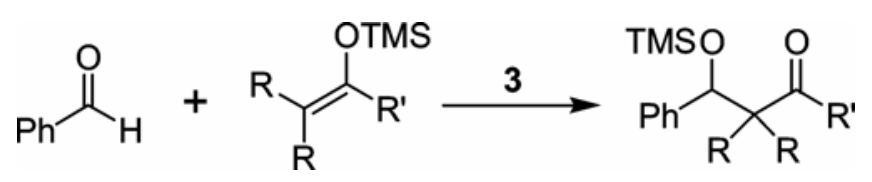

Scheme 5. network with the $\mathrm{Cu}$... Cu distance of 15.62(2) $\AA$. The void space was filled with one $\mathrm{MeOH}$ and two $\mathrm{H}_{2} \mathrm{O}$ guest molecules through hydrogen bonding. The catalytic activity of $\mathbf{4}$ towards asymmetric ringopening reactions of epoxides with aromatic amines was examined (scheme 7). In this reaction, the heterogeneous 4 was able to catalyse the synthesis of optically active $\beta$-amino alcohols. Interestingly, the yields of the $\beta$-amino alcohols was impressive when the reaction was carried out under the solvent free conditions. A maximum yield of $54 \%$ and $50 \%$ ee were obtained under the solvent free conditions. It may, however, be noted that the mechanistic details about the ring-opening reaction were not reported. However, the $\mathrm{Cu}$ (II) ions in $\mathbf{4}$ are four-coordinate and further increase of coordination number may be responsible for the observed catalytic behaviour.

Blake and co-workers ${ }^{12 \mathrm{a}}$ reported a $\mathrm{Cu}$-based polymer, $\left[\mathrm{Cu}\left(4,4^{\prime}\right.\right.$-bipyridine $)\left(\mathrm{H}_{2} \mathrm{O}\right)_{2}\left(\mathrm{BF}_{4}\right)_{2}\left(4,4^{\prime}\right.$-bipyridine) $]_{\alpha} 5$ with the hydrogen-bond regulated dynamic framework. The MOF network of $\mathbf{5}$ consists of 2D sheets, each of which is composed of octahedral $\mathrm{Cu}$ (II) sites linked directly via coordinating 4,4'-bipyridine units and also via 4,4'-bipyridine units and intermediate $\mathrm{H}$-bonded water molecules (scheme 8). The sheets are connected by the hydrogen bonding between an $\mathrm{F}$ atom of a $\mathrm{BF}_{4}^{-}$anion on axial positions from a sheet and an $\mathrm{H}$ atom of a water molecule from the neighbouring sheet. Two adjacent sheets are slightly shifted to each other and thus the open structure is blocked. Although the MOF structure of $\mathbf{4}$ has no open micro-pores and unsaturated coordination metal sites, it can adsorb $\mathrm{CO}_{2}$ after partial removal of the water molecules.

Baiker and co-workers ${ }^{12 \mathrm{~b}}$ utilized the MOF 5 as a highly active, recyclable heterogeneous catalyst for the alcoholysis of epoxides (scheme 9). Conversion and selectivity $(>90 \%)$ were achieved at room temperature in only $2 \mathrm{~h}$. Importantly, no reaction occurred without the catalyst under the similar conditions. For comparison, the homogeneous catalyst $\mathrm{Cu}\left(\mathrm{BF}_{4}\right)_{2}$. $\mathrm{H}_{2} \mathrm{O}$ was only slightly more active and selective than 5. Interestingly, when pyridine in conjunction with $\mathrm{Cu}\left(\mathrm{BF}_{4}\right)_{2} \cdot \mathrm{H}_{2} \mathrm{O}$ was used in place of $4,4^{\prime}-$ bipyridine, a much lower conversion resulted with complete loss of activity at pyridine/ $\mathrm{Cu}$ ratio of 40 . This effect was explained mainly due to the coordination of $\mathrm{Cu}$ (II) ion with pyridine, which hinders the access of substrate to the copper active sites. Substrates that were successfully tested included aromatic and aliphatic epoxides. 


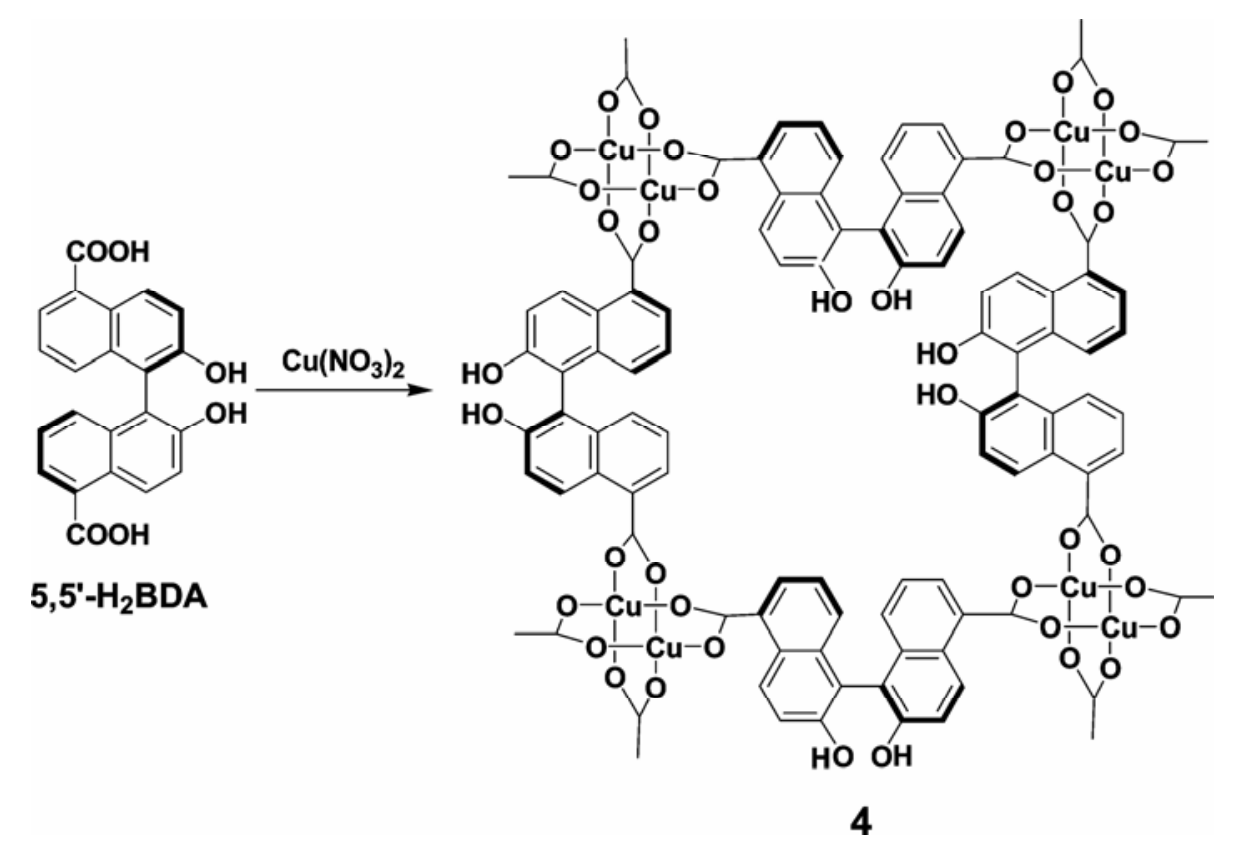

Scheme 6.

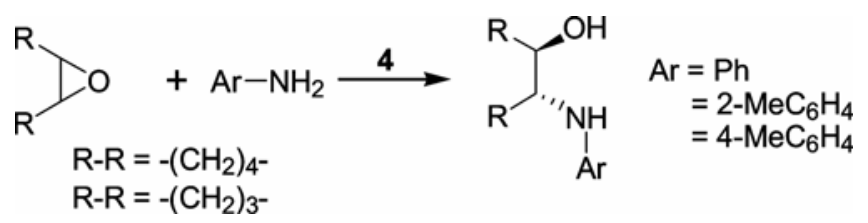

Scheme 7.

Lin and co-workers ${ }^{13}$ have employed the axially chiral bridging ligand $(R)-6,6^{\prime}$-dichloro-2, $2^{\prime}$-dihydroxy-1, $1^{\prime}$-binaphthyl-4,4'-bipyridine $\left(\mathbf{L}^{1}\right)$ which contain the bipyridyl primary functional groups and orthogonal chiral 2,2'-dihydroxy secondary functional groups to construct the homochiral porous MOFs, $\left[\mathrm{Cd}_{3} \mathrm{Cl}_{6}\left(\mathbf{L}^{1}\right)_{3}\right] .4 \mathrm{DMF} \cdot 6 \mathrm{MeOH} \cdot 3 \mathrm{H}_{2} \mathrm{O} 6$ (scheme 10). Octahedrally coordinated $\mathrm{Cd}(\mathrm{II})$ ions in 6 are doubly bridged by the $\mathrm{Cl}^{-}$ions to form 1D zigzag $\left[\mathrm{Cd}(\mu-\mathrm{Cl})_{2}\right]_{\alpha}$ chains that serve as the secondary building units (SBUs). Each $\mathrm{Cd}(\mathrm{II})$ center in 1D chain further coordinates to two pyridyl groups of the ligand $\mathbf{L}^{1}$ and connects $1 \mathrm{D}\left[\mathrm{Cd}(\mu-\mathrm{Cl})_{2}\right]_{\alpha}$ SBUs to form a non-interpenetrating 3D network with very large rectangular chiral channels of $1.6 \times 1.8 \mathrm{~nm}$. The dihydroxy groups for two $\mathbf{L}^{1}$ are shielded from the open channels by the naphthyl rings whereas the third $\mathbf{L}^{1}$ ligand of $\mathbf{6}$ is available to coordinate an appropriate secondary metal ion. The exposed dihydroxy groups for two $\mathbf{L}^{1}$ were then treated with the $\mathrm{Ti}\left(\mathrm{O}^{\mathrm{i}} \mathrm{Pr}\right)_{4}$ to generate $\mathbf{6}-\mathbf{T i}$ heterobimetallic MOF networks. The resultant $\mathbf{6}-\mathbf{T i}$ acted as an efficient
Lewis acidic catalyst for the nucleophilic addition of $\mathrm{ZnEt}_{2}$ to a range of aromatic aldehydes with complete conversion to the alcohol product (scheme 11). The aldehydes were able to access the active Ti sites located within the interior of the framework. A series of aldehydes with sizes ranging from $0.8 \mathrm{~nm}$ to $2.0 \mathrm{~nm}$ were tested and the data suggested that larger aldehydes gave lower conversion inside the crystal channels presumably due to hindered access to the catalytic Ti sites.

Hupp and co-workers ${ }^{14}$ have demonstrated that by appropriate design of organic building blocks, metalloporphyrins can be successfully incorporated into a MOF possessing the features needed for effective catalysis, i.e. large pores, permanent micro porosity, and fully reactant-accessible active sites. The authors used mixed-ligand strategy for incorporating metallo-porphyrins into the frameworks featuring large pores that are suitable for catalysis. They used the tetra topic, 'octa'-oxygen ligand 1,2,4,5-tetrakis (4-carboxyphenyl)benzene $\left(\mathbf{L}^{2}\right)$ in place of the more conventional dicarboxylic acids. This design element had the advantage of increased chelating ability of $\mathbf{L}^{2}$ to provide greater stability, and thus permanent micro porosity, to the resulting MOF. Combining $\mathrm{Zn}\left(\mathrm{NO}_{3}\right)_{2} \cdot 6 \mathrm{H}_{2} \mathrm{O}, \mathrm{L}^{2}$, and (5,15-dipyridyl10,20-bis(pentafluorophenyl))porphyrin $\left(\mathbf{L}^{3}\right)$ under solvothermal conditions afforded 7, a zinc based, pillared paddlewheel MOF with the formula $\left[\mathrm{Zn}_{2}\right.$ $\left.\left(\mathbf{L}^{2}\right)\left(Z n-\mathbf{L}^{3}\right)\right]$ (scheme 12). As expected, the free- 


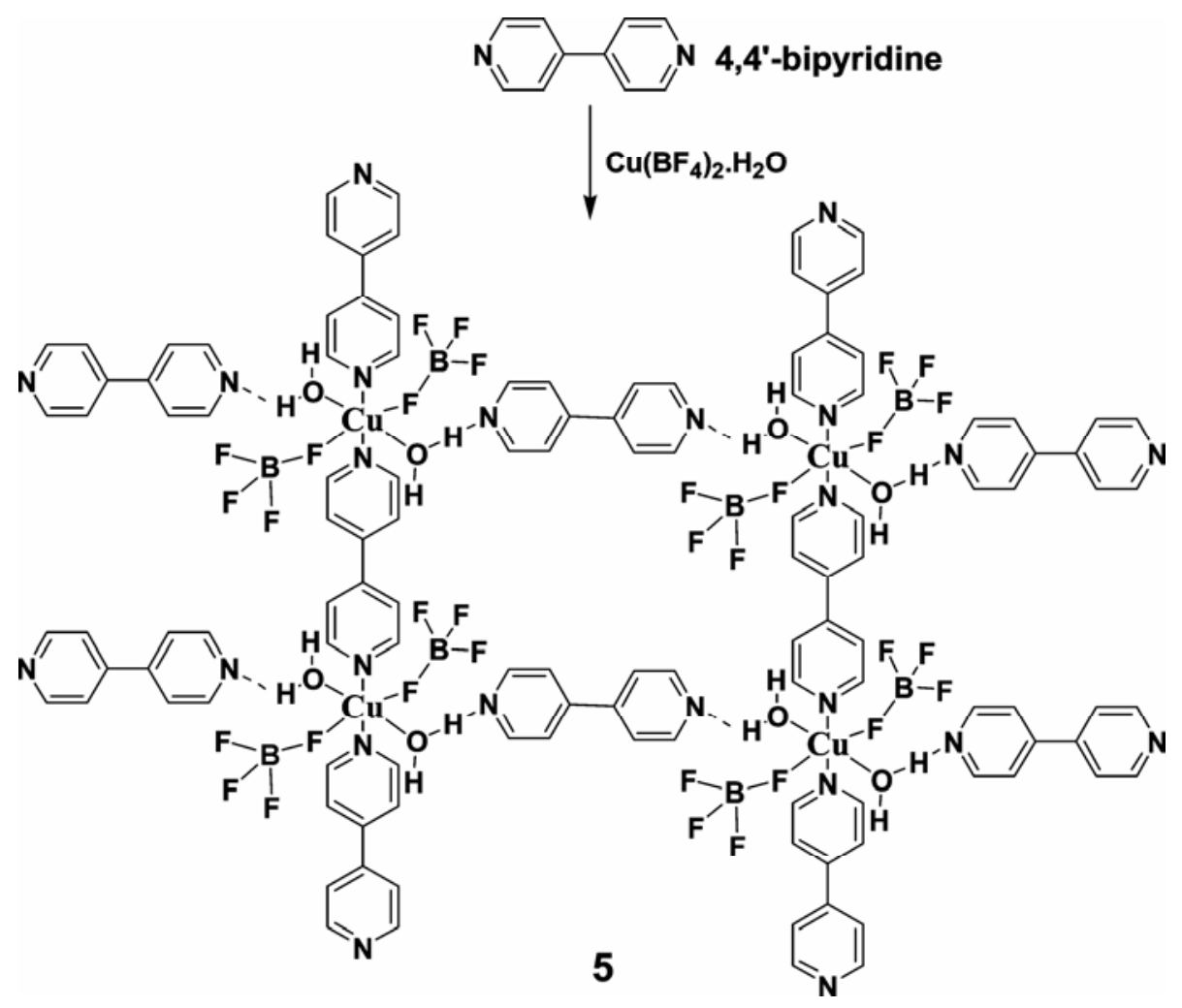

Scheme 8.<smiles>COC(CO)c1cccc(C=CO)c1</smiles>

Scheme 9.

base porphyrin $\mathbf{L}^{3}$ was metalated during the course of the solvothermal synthesis. The crystal structure of 7 revealed large channels in three directions that were occupied by a substantial amount of disordered solvent molecules. Notably, 7 comprises a single independent framework, suggesting a high degree of porosity. Proof-of-concept catalysis of an acyltransfer reaction between $N$-acetylimidazole and 3-pyridylcarbinol revealed 2400-fold rate enhancement, dominated by contributions from Lewis acid activation and reactant pre-concentration (scheme 13).

Ferey and co-workers ${ }^{15 a}$ have synthesized MOF 8 $\left[\mathrm{Cr}_{3} \mathrm{X}\left(\mathrm{H}_{2} \mathrm{O}\right)_{2} \mathrm{O}(\mathrm{bdc})_{3}\right] \quad\left(\mathrm{X}=\mathrm{F}, \quad \mathrm{OH}, \quad \mathrm{H}_{2} \mathrm{O} ; \quad\right.$ bdc $=$ benzene-1,4-dicarboxylate) that showed a very high surface area and high pore volume as compared to other porous coordination polymers. MOF 8 con- sisted of $\mu_{3}$-oxo bridged chromium(III)-trimers cross-linked by the terephthalate groups. The $\mathrm{Cr}$ ions have a pseudo-octahedral coordination. The vertices of these pseudo-octahedra are occupied by $\mu_{3}-\mathrm{O}$ atom in the middle of the chromium trimers and four oxygen atoms derived from the carboxylate groups of the terephthalate linkers. The coordination sphere around each chromium ion is completed by a water molecule, a fluorine atom or a hydroxyl group. Kaskel and co-workers ${ }^{15 b}$ utilized MOF 8 as the heterogeneous catalyst for the cyanosilylation reaction of the aldehydes (scheme 2). According to these authors, MOF 8 has a much higher activity towards the addition of trimethylsilylcyanide to benzaldehyde even at $0.5 \%$ catalyst loading. Further, the recycling experiments were performed and show the product yield of $98.5 \%$ in the first run, whereas somewhat lower $91.5 \%$ and $91.3 \%$ product yields were obtained in the second and third run, respectively. The robustness of MOF 8 was confirmed by recording the powder XRD pattern of the sample before and after the catalytic investigation that display similar diffraction pattern.

Monge and co-workers ${ }^{16}$ have synthesized an indium containing MOF $\left[\operatorname{In}\left(\mathrm{L}^{4}\right)(\mathrm{OH})\right] \mathbf{9}$, with a bent 


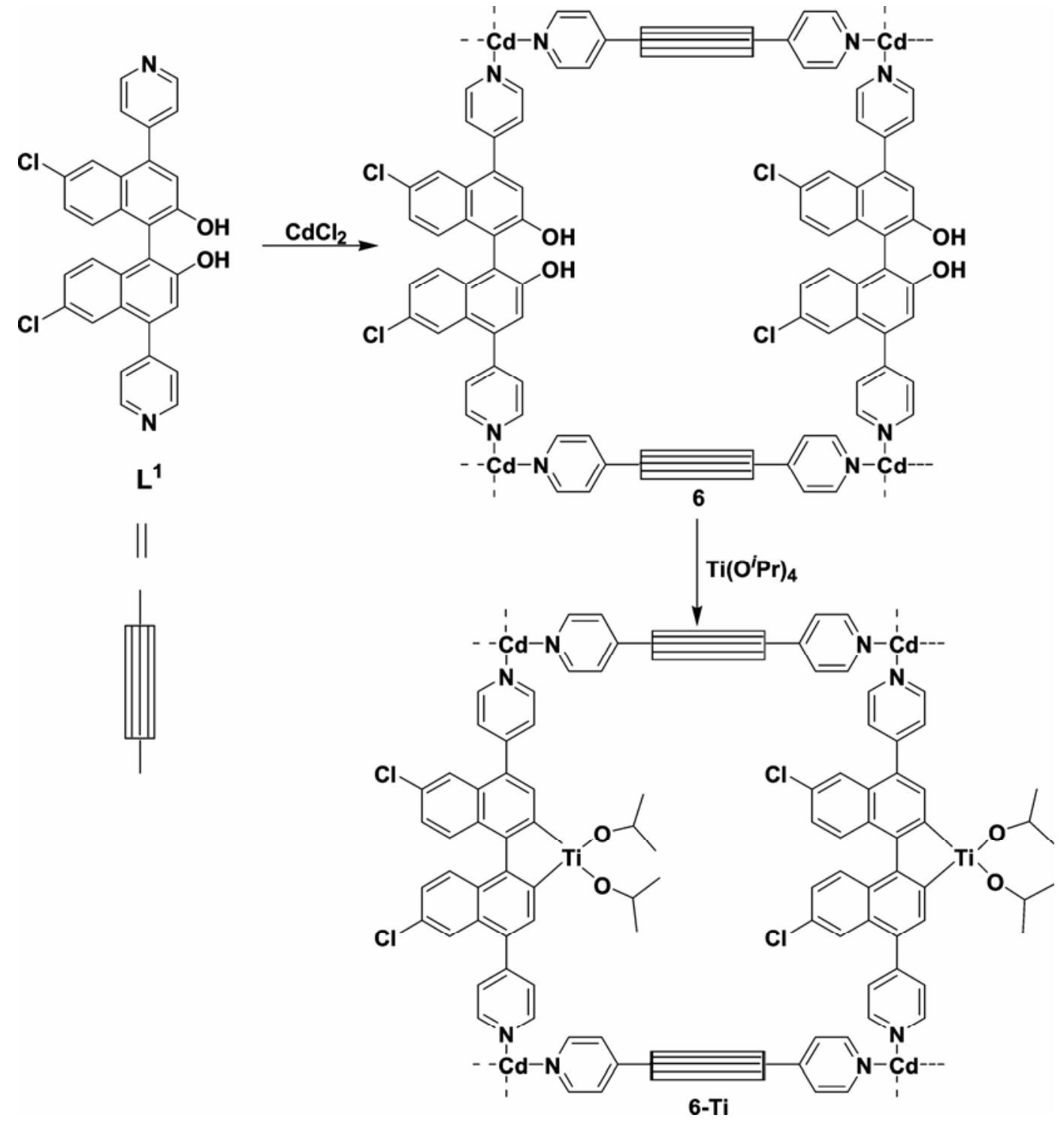

Scheme 10.

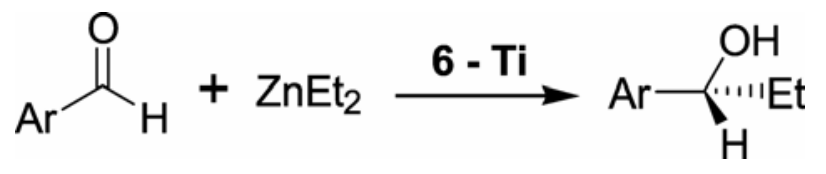

Scheme 11.

linker, 4,4'-(hexafluoroisopropylidene)bis(bezoic acid), $\mathbf{L}^{4}$ (scheme 14). In this complex, the indium ion is coordinated to two $\mu_{2}-\mathrm{OH}$ groups in apical positions and to four different deprotonated carboxylate linking ligands, $\mathbf{L}^{4}$. Chains of sharing vertex $\operatorname{In}(\mathrm{O})_{6}$ octahedra run along the $a$ direction via $\mu_{2}-\mathrm{OH}$ and bridging carboxylate groups. The bent carboxylate-based linker was coordinated to four different indium atoms (two of each chain) and chain in $b$ direction give rise to thick layers perpendicular to the $c$ direction. The square-shaped channel running down $a$ axis were formed inside each layer. $\left[\operatorname{In}\left(\mathrm{L}^{4}\right)(\mathrm{OH})\right] 9$ is a nano-porous and thermally stable compound and was tested for the Lewis acid catalysed acetalization reaction of aldehyde with trimethyl orthoformate (scheme 15). The reaction produced the corresponding dimethylacetal in quantitative yield in a short time $(1 \mathrm{~h})$ with high turnover-frequency (TOF). The bulkier $\alpha$-methylbenzeneacetaldehyde was poorly reactive and took longer reaction time $(72 \mathrm{~h})$, showing the hindrance to the diffusion of the reactants within the MOFs pores. Interestingly, when a guest (pyridine) 


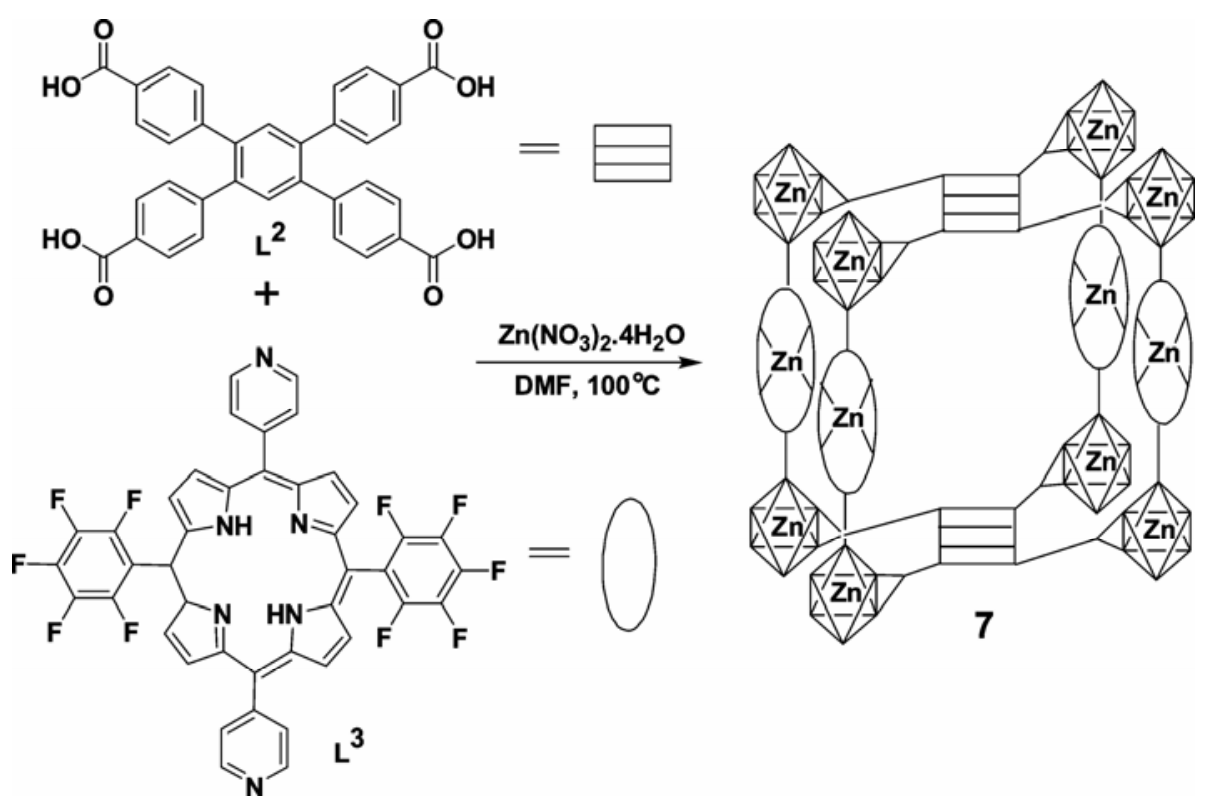

Scheme 12.

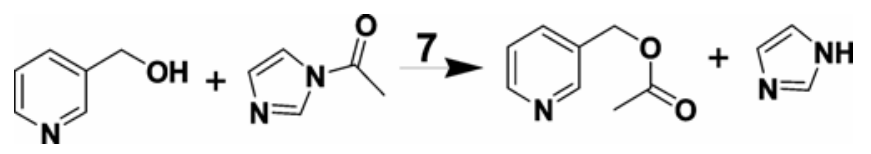

Scheme 13.

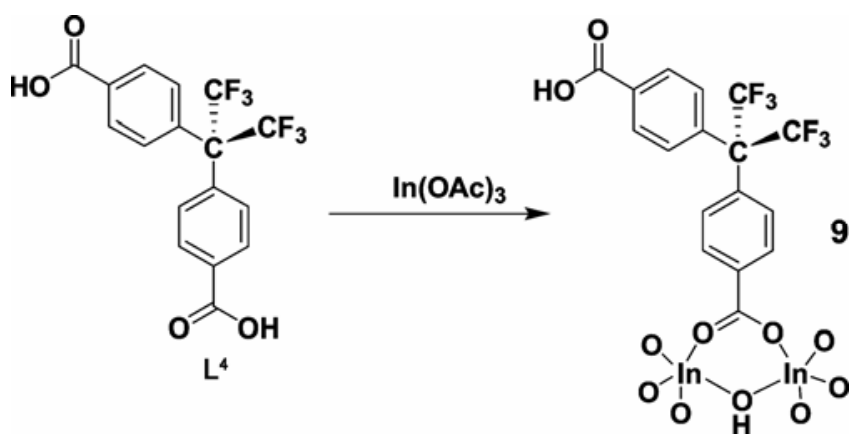

Scheme 14.

$\underset{\mathrm{R}_{1}}{\stackrel{\mathrm{O}}{\mathrm{R}_{2}}}+\mathrm{ZnEt}_{2}+\mathrm{HC}\left(\mathrm{OCH}_{3}\right)_{3} \stackrel{\mathbf{9}}{\longrightarrow} \underset{\mathrm{R}_{1}}{\mathrm{H}_{3} \mathrm{CO}}>_{\mathrm{R}_{2}}^{\mathrm{OCH}_{3}}$

Scheme 15.

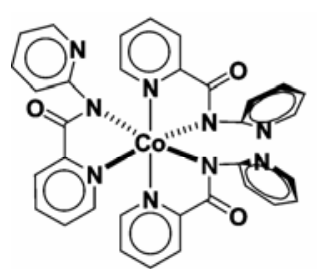

10

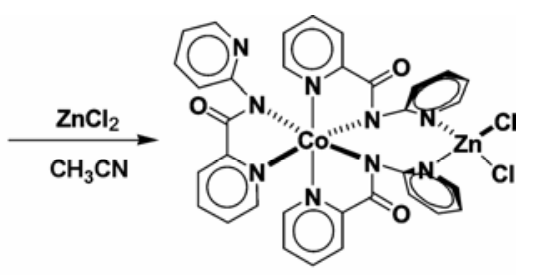

12 occupied MOF, $\left[\operatorname{In}\left(\mathrm{L}^{4}\right)(\mathrm{OH})\right] \cdot$ pyridine (9.pyridine) was used, a low transformation and poor TOF resulted. This experiment clearly pinpointed that the catalysis is taking place within the pores of the MOF.

Gupta and co-workers ${ }^{17-19}$ have adopted a much simpler strategy to incorporate Lewis acidic metal ions in a multi-component structure. The authors aimed to place an exposed Lewis acidic metal centre at the periphery of the molecule for better accessibility of the substrates. For this purpose, few cobalt(III) complexes (10 and 11) of pyridine-amide ligands were synthesized and demonstrated as the building blocks. ${ }^{17}$ The ligand coordinated the cobalt ion via $\mathrm{N}_{\text {amide }}$ and $\mathrm{N}_{\text {pyridine }}$ centers while leaving one or two of the tethered pyridine ring un-coordinated or hanging. The geometry of the Co(III) ion oriented the tethered pyridine rings with a definite directionality to coordinate a secondary metal ion thus making suitable monomeric building blocks for preparing heterobimetallic complexes. The building blocks $\mathbf{1 0}$ and $11^{17}$ were subsequently used for the preparation of $\left\{\mathrm{Co}^{3+}-\mathrm{Zn}^{2+}\right\} 12$ and $\left\{\mathrm{M}^{2+}-\mathrm{Co}^{3+}-\mathrm{M}^{2+}\right\}\left(\mathrm{M}^{2+}=\mathrm{Zn}\right.$, $\mathrm{Cd}$, and $\mathrm{Hg}$ ) heterobimetallic complexes 13, 14, and 15 (schemes 16 and 17). ${ }^{18,19}$

The selection of the peripheral metal ion was based on the possible application of the exposed Lewis acidic metal ion in organic transformations. Indeed, the Lewis acidic property of the peripheral $\mathrm{Zn}^{2+}$ ion was demonstrated by the catalytic Beck-

Scheme 16. 


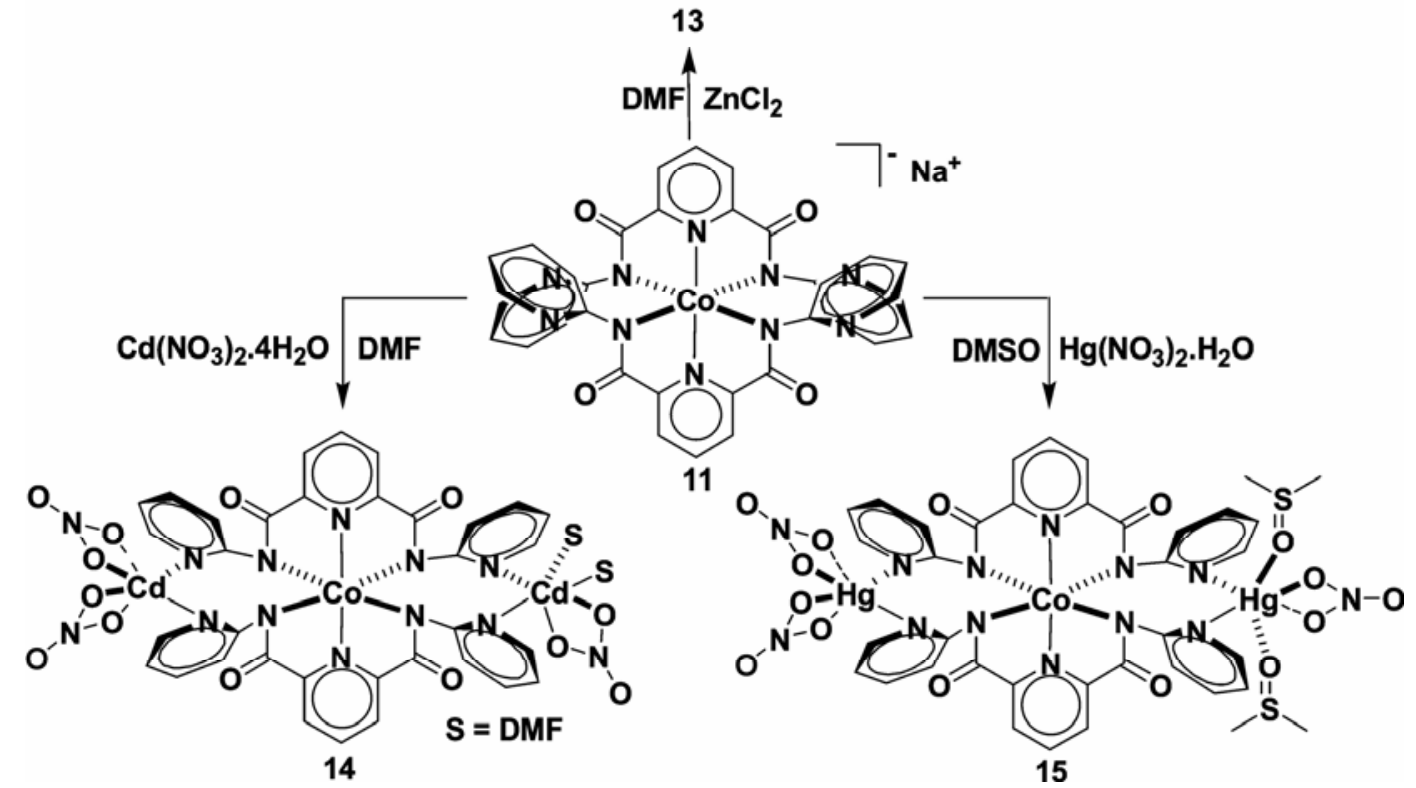

Scheme 17.<smiles>[R]NC([R2])=O</smiles>

$\mathrm{R}_{1}=\mathrm{H}, \mathrm{Ph}, p-(\mathrm{OMe}) \mathrm{C}_{6} \mathrm{H}_{4}, p-(\mathrm{Cl}) \mathrm{C}_{6} \mathrm{H}_{4}, p-\left(\mathrm{NO}_{2}\right) \mathrm{C}_{6} \mathrm{H}_{4}$ $\mathrm{R}_{2}=\mathrm{CH}_{3}, \mathrm{Ph}, p-(\mathrm{OMe}) \mathrm{C}_{6} \mathrm{H}_{4}, p-(\mathrm{Cl}) \mathrm{C}_{6} \mathrm{H}_{4}, p-\left(\mathrm{NO}_{2}\right) \mathrm{C}_{6} \mathrm{H}_{4}$

Scheme 18.

ketoximes producing the corresponding amides (scheme 18). ${ }^{18}$ Complex 13 was found to be the most effective catalyst for the $\mathrm{BR}$ reaction. The inability of the complex 12 and [(pyridine) $\left.{ }_{2} \mathrm{ZnCl}_{2}\right]$ to promote $\mathrm{BR}$ reaction strongly implicated that the labile site is essential for the observed catalytic activity. The authors reasoned that the coordinated solvent molecule in $\mathbf{1 3}$ was first replaced by the oxime in the initiation step. This speculation is further supported by the fact that the ketoxime with sterically demanding substituents, such as benzophenone-oxime did not give any BR products, as the substrate was, probably, unable to approach the $\mathrm{Zn}$ center. ${ }^{18}$ Most importantly, the catalyst 13 can be isolated after the reaction and reused (tested for 8 times) without significant drop in the catalytic performance. Furthermore, the analogous complexes 14 and $\mathbf{1 5}$ did not show the BR reaction under the similar reaction conditions ${ }^{20}$ thus confirming the uniqueness of the $\mathrm{Zn}^{2+}$ ions in heterobimetallic complex 13 for the observed catalytic $\mathrm{BR}$ reactivity.

Gupta and co-workers ${ }^{19}$ also tested the $\left\{\mathrm{Zn}^{2+}-\right.$ $\left.\mathrm{Co}^{3+}-\mathrm{Zn}^{2+}\right\} 13,\left\{\mathrm{Cd}^{2+}-\mathrm{Co}^{3+}-\mathrm{Cd}^{2+}\right\} 14$, and $\left\{\mathrm{Hg}^{2+}-\right.$ $\left.\mathrm{Co}^{3+}-\mathrm{Hg}^{2+}\right\} 15$ heterobimetallic complexes for the Strecker reaction (cyanation of imines). At $2 \mathrm{~mol} \%$ loading, compound $\mathbf{1 4}$ afforded the desired products in $80-95 \%$ yields within $4 \mathrm{~h}$ with TOF in the range of $10-12 \mathrm{~h}^{-1}$ (scheme 19). A variety of substrates were tested and the results indicate the general nature of the reaction.

It may be noted that no reaction was observed in the absence of complex 14. These catalytic reactions were also tested with the analogous $\mathrm{Zn}-(\mathbf{1 3})$ and $\mathrm{Hg}$-complexes (15); which showed very poor reactivity ( $<5 \%$ by GC). It was suggested that the availability of the labile solvent molecules on the cis position in $\left\{\mathrm{Cd}^{2+}-\mathrm{Co}^{3+}-\mathrm{Cd}^{2+}\right\}$ complex 14 provided 
the desired access to the substrate as well as the nucleophile $\left(\mathrm{CN}^{-}\right)$to interact in a concomitant manner. In comparison, the trans arrangement of the solvent molecules in complex $\mathbf{1 5}$ and the availability of only one labile site in complex $\mathbf{1 3}$ restricted the proposed interaction of the nucleophile with that of substrate in a concomitant manner. ${ }^{19}$

Ring opening reactions of the oxiranes (epoxides) and thiiranes with various nucleophiles are attractive due to applications in the synthesis of biologically important compounds. ${ }^{21}$ The authors nicely demonstrated the role of relative size and Lewis acidic property of the catalytic metal ion; and the preferential binding of the substrate to catalytic metal atom on the ring-opening reactions. ${ }^{19}$ Cyclohexene oxide was opened with aniline or para-substituted aniline in the presence of $5 \mathrm{~mol} \%$ catalyst (scheme 20). All three $\left\{\mathrm{M}^{2+}-\mathrm{Co}^{3+}-\mathrm{M}^{2+}\right\}$ catalysts $(\mathrm{M}=\mathrm{Zn}, \mathrm{Cd}$, and $\mathrm{Hg}$ ) were tested, however, the reaction was best

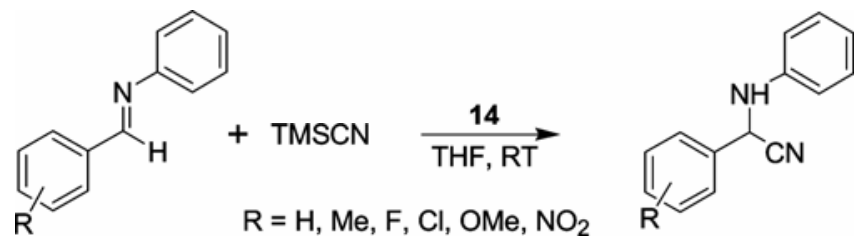

Scheme 19.

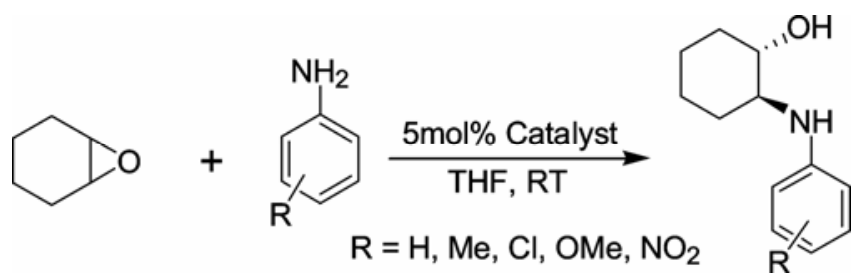

Scheme 20.

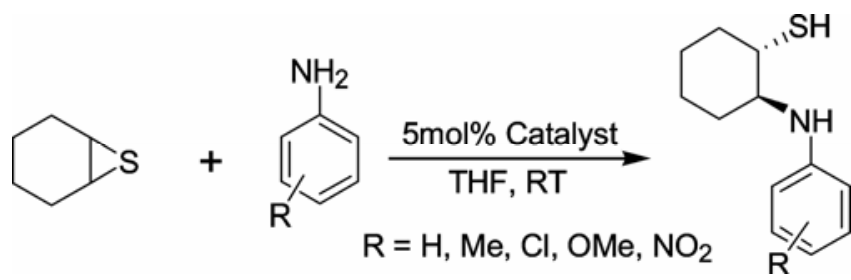

Scheme 21.

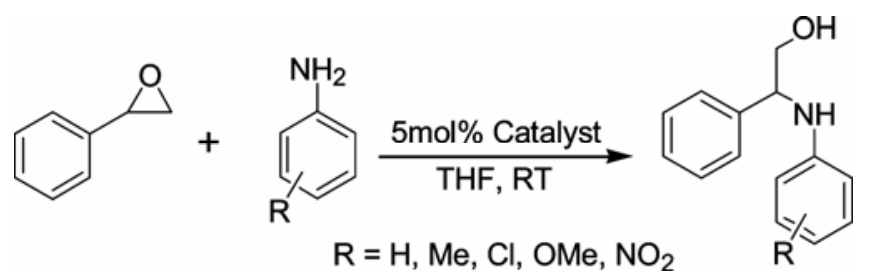

Scheme 22. catalysed by the $\left\{\mathrm{Cd}^{2+}-\mathrm{Co}^{3+}-\mathrm{Cd}^{2+}\right\}$ complex 14 . In the case of cyclohexene sulfide, the $\mathrm{Hg}$-catalyst, 15 was superior to others (scheme 21). It was suggested that the strong affinity of the $\mathrm{Hg}$ (II) ion to softer sulfur atom was the primary reason for the ringopening reaction in an efficient manner. ${ }^{19}$

To determine the regioselectivity, styrene oxide ${ }^{22}$ was opened with aniline or $p$-substituted aniline (scheme 22). Interestingly, a perfect regioselectivity was observed that resulted in only a single product in all cases with all three catalysts. ${ }^{19}$ There are however, two possibilities due to the nucleophilic attack either at the benzylic carbon atom or at the less hindered carbon atom of the epoxide ring. Interestingly, in all cases, nucleophilic attack took place at the benzylic carbon atom of the epoxide. This plausibly suggest that the epoxide has interacted with the peripheral metal atom $(\mathrm{Zn}, \mathrm{Cd}$, or $\mathrm{Hg})$ through the less-hindered side due to the steric reasons.

\section{Summary and conclusion}

As summarized in this paper, the last few years have seen a significant progress in the field of organic transformations by the multi-component structures including MOFs and MOCNs. Especially MOFs and MOCNs-based catalysis has shown that it is possible to have the catalytic applications of the material somewhat closer to that of zeolites. The thorough understanding of the nature of the active catalytic site opens up the possibility to create new and cheaper catalytic systems. Compared to the high thermal and hydrolytic stability of the zeolites, MOFs and MOCNs are clearly inferior; however, on the other hand, tunability, regularity of the catalytic sites, and possible homochirality compensate some of the drawbacks. An attractive feature that MOFs and MOCNs-based catalytic systems offer is the wide scope of various types of organic transformations possible within the porous networks of the material. The field is still in its development stage and next few years may demonstrate selective catalytic behaviour that is unique to MOFs and other multi-component structures and assemblies. We thus envisage that this particular class of materials would find many new applications in the future.

\section{Acknowledgements}

$\mathrm{R} \mathrm{G}$ is thankful to the Department of Science and Technology (DST), Government of India for the 
generous financial support. AA and APS, respectively thank University Grants Commission (UGC) and Council for Scientific and Industrial Research (CSIR) for the fellowships.

\section{References}

1. (a) Corma A 1997 Chem. Rev. 97 2373; (b) Davis M E 1993 Acc. Chem. Res. 26111

2. (a) Seff K 1976 Acc. Chem. Res. 9 121; (b) Anderson M W, Terasaki O, Ohsuna T, Philippou A, Mackay S P, Ferreira A, Rocha J and Lidin S 1994 Nature 367 347; (c) Newsan J M, Treacy M M J, Koetsier W T and de Gruyter C B 1988 Proc. R. Soc. London, Ser. A 420375

3. Sachtler W M H 1993 Acc. Chem. Res. 26383

4. (a) Moulton B and Zaworotko M J 2001 Chem. Rev. 101 1629; (b) Ferey G, Mellot-Draznieks C, Serre C and Millange F 2005 Acc. Chem. Res. 38 217; (c) Yaghi O M, O'Keeffe M, Ockwig N W, Chae H K, Eddaoudi M and Kim J 2003 Nature 423 705; (d) Hill R J, Long D L, Champness N R, Hubberstey P and Schroder M 2005 Acc. Chem. Res. 38 335; (e) Bradshaw D, Warren J E and Rosseinsky M J 2007 Science 315977

5. Tranchemontagne D J, Mendoza-Cortés J L, O'Keeffe M and Yaghi O M 2009 Chem. Soc. Rev. 381257

6. (a) Ma L, Abney C and Lin W 2009 Chem. Soc. Rev. 38 1248; (b) Lee J Y, Farha O K, Roberts J, Scheidt K A, Nguyen, S T and Hupp J T 2009 Chem. Soc. Rev. 381450

7. O'Keeffe M 2009 Chem. Soc. Rev. 381215

8. Fujita M, Kwon Y J, Washizu S and Ogura K $1994 \mathrm{~J}$. Am. Chem. Soc. 1161151

9. Ohmori O and Fujita M 2004 Chem. Commun. 1586

10. (a) Horike S, Dinca M, Tamaki K and Long J R 2008 J. Am. Chem. Soc. 130 5854; (b) Dinca M, Dailly A,
Liu Y, Brown C M, Neumann D A and Long J R 2006 J. Am. Chem. Soc. 12816876

11. Tanaka K, Oda S and Shiro M 2008 Chem. Commun. 820

12. (a) Blake A J, Hill S J, Hubberstey P and Li W S 1997 J. Chem. Soc. Dalton Trans. 913; (b) Jaing D, Mallat T, Krumeich F and Baiker A $2008 \mathrm{~J}$. Catal. 257390

13. Wu C-D, $\mathrm{Hu} \mathrm{A}$, Zhang $\mathrm{L}$ and Lin W $2005 \mathrm{~J}$. Am. Chem. Soc. 1278940

14. Shultz A M, Farha O K, Hupp J T and Nguyen S T 2009 J. Am. Chem. Soc. 1314204

15. (a) Ferey G, Mellot-Draznieks C, Serre C, Millange F, Dutour J, Surble S and Margiolaki I 2005 Science 309 2040; (b) Henschel A, Gedrich K, Kraehnert R and Kaskel S 2008 Chem. Commun. 4192

16. Gandara F, Gomez-Lor B, Gutiaerrez-Puebla E, Iglesias M, Monge M A, Proserpio D M and Snejko N 2008 Chem. Mater. 2072

17. Mishra A, Kaushik N K, Verma A K and Gupta R 2008 Eur. J. Med. Chem. 432189

18. Mishra A, Ali A, Upreti S and Gupta R 2008 Inorg. Chem. 47154

19. Mishra A, Ali A, Upreti S, Whittingham M S and Gupta R 2009 Inorg. Chem. 485234

20. Mishra A, Ali A and Gupta R 2010 (unpublished results)

21. (a) Connolly M E, Kersting F and Bollery C T 1976 Prog. Cardiovasc. Dis. 19 203; (b) Triggle D J 1981 In Burger's medicinal chemistry (ed.) M S Wolff (New York: Wiley-Interscience) 4th edn, p. 225; (c) De Cree J, Geukens H, Leempoels J and Verhaegen H 1986 Drug Dev. Res. 8 109; (d) Young R R, Gowen J H and Shahani B T 1975 N. Engl. J. Med. 293 950; (e) Joossens J, Vander-Veken P, Lambeir A M, Augustyns K and Haemers A $2004 \mathrm{~J}$. Med. Chem. 472411

22. Shivani, Pujala B and Chakraborti, A K 2007 J. Org. Chem. 723713 